\title{
Influence of Water and Ultraviolet Irradiation on the Induction Period of the Oxidation of Biodiesel
}

\author{
Willian L. G. da Silva, ${ }^{a}$ Acacia A. Salomão, ${ }^{a}$ Marta M. D. C. Vila ${ }^{b}$ and \\ Matthieu Tubino $*, a$ \\ anstituto de Química, Universidade Estadual de Campinas (UNICAMP), P. O. Box 6154, \\ 13083-970 Campinas-SP, Brazil \\ ${ }^{b}$ Departamento de Farmácia, Universidade de Sorocaba (UNISO), 18023-000 Sorocaba-SP, Brazil
}

\begin{abstract}
Biodiesel degrades due to oxidative processes, causing a decrease in its quality. In the present work, it has been clearly shown that the incidence of ultraviolet radiation on biodiesels obtained from soy, canola, linseed and microalgae oils initiate oxidative processes which lead to the decrease in the induction period (IP) of the fuel. The influence of the residual water content of the same biodiesels on the oxidation process was also investigated with and without the incidence of ultraviolet radiation. Between 190 and $850 \mathrm{ppm}$ of water in the biodiesel and without UV irradiation, no significant change in the IP values was observed under the experimental conditions.
\end{abstract}

Keywords: biodiesel, oxidative stability, photo-oxidation, residual water

\section{Introduction}

Biodiesel is a biofuel derived from renewable sources such as vegetable oils and animal fats. It presents physicochemical characteristics similar to that of petrodiesel and can therefore be directly used in diesel engines. Because biodiesel is produced from renewable and biodegradable raw materials, it presents some advantages over petrodiesel, for example, the absence of sulfur in emissions, a high flash point, and good lubricity. ${ }^{1,2}$

Biodiesel is composed of a mixture of alkyl esters, usually methyl or ethyl derivatives, obtained through transesterification reactions of vegetable oils and animal fats with methanol or ethanol in the presence of a catalyst.

Oxidation reactions of biodiesel can occur on account of various factors, such as high unsaturation and total number and position of allylic and bis-allylic carbons that are adjacent to the double bonds of the molecules of alkyl esters, exposure to light, temperature, presence of transition metals, and exposure to oxygen. ${ }^{3-5}$ It was also reported that hydrolysis reactions can occur depending on the environmental humidity or even on the humidity present in the storage tanks. Residual water is particularly problematic because it can hydrolyze the biodiesel, producing free fatty acids and alcohol and increasing the acid number of biodiesel. ${ }^{6}$

*e-mail: tubino@iqm.unicamp.br
Similar to lipids, the oxidation of biodiesel occurs mainly through two processes called auto-oxidation and photo-oxidation. Auto-oxidation is the main cause of the oxidation of biodiesel. It involves the formation of free radicals and can be summarized in three steps called initiation, propagation, and termination, as schematized in Figure $1 .^{7}$ In the first phase, known as the induction or initiation period, the initial formation of free radicals occurs. In the second phase, known as propagation, the formation of a great quantity of peroxides and hydroperoxides occurs. Finally, the termination step occurs, forming high concentrations of degradation products, such as alcohols, aldehydes, ketones, organic acids, and polymers, whose presence changes the properties of the biodiesel..$^{8,9}$

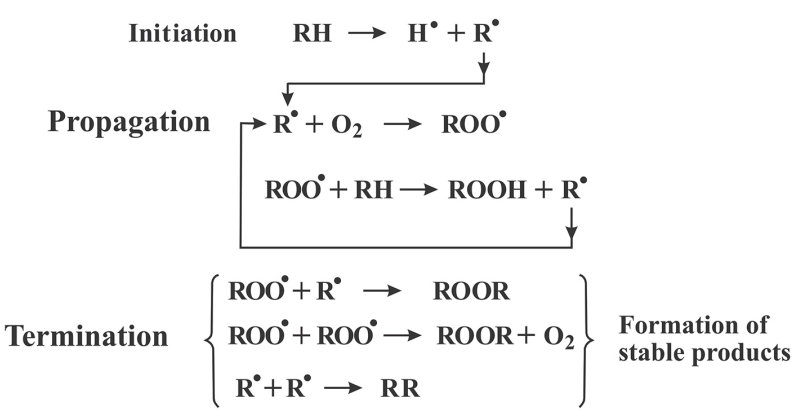

Figure 1. Lipid oxidation reaction; $\mathrm{RH}$ : unsaturated fatty acid, $\mathrm{R}^{\bullet}$ : free radical, ROO*: peroxide radical and $\mathrm{ROOH}$ : hydroperoxide. 
Another type of oxidation reaction that biodiesel can undergo is the photo-oxidation. Free radicals, which are known as initiators of oxidation processes, are formed as a result of photo-chemical reactions. ${ }^{10}$

With the formation of the oxidized compounds, the biodiesel becomes more viscous. The formed hydroperoxides can induce the polymerization of esters, leading to the generation of insoluble gums and other sediments, which can cause the fuel filter to clog. ${ }^{11}$ Additionally, the acidity of the biodiesel increases, thus inducing corrosive processes. ${ }^{8}$ Other properties are also affected, such as the cetane number, the flash point, the refraction index, and the dielectric constant. ${ }^{9}$

Bondioli et al. ${ }^{12}$ observed that the residual water in biodiesel stored at $20{ }^{\circ} \mathrm{C}$ does not cause changes in the acid number. However, in tests at $40{ }^{\circ} \mathrm{C}$ and with water contents higher than $0.1 \%$, an increase in the acidity was observed after 6 months of storage. It has been reported that the purity and the acid number of the biodiesel remained almost unaltered in the presence of water over 50 weeks. These observations show that although water is considered to be a factor promoting the degradation of biodiesel via hydrolysis, its effect is much smaller than that of oxygen and temperature. ${ }^{1,13}$

To evaluate the deterioration of biodiesel with respect to the storage conditions, various analytical parameters have been employed. Among them are the oxidative stability at $110{ }^{\circ} \mathrm{C}$, the peroxide number, the acid number, the viscosity, the iodine number, and the presence of insoluble impurities. ${ }^{10,14,15}$ According to the EN 14112 (2003) method, ${ }^{16}$ the Rancimat ${ }^{\circledR}$ method is used to determine the oxidation stability of biodiesel, for which the induction period (IP) is also determined.

Independently of the oil used to prepare biodiesels, a central point that merits attention is the resistance of the biodiesel to oxidation because this property, expressed by IP, is of fundamental importance to estimated the time of storage. ${ }^{2,17}$ With this fact in mind, the aim of this work was to evaluate the effect of the concentration of residual water and the effect of ultraviolet irradiation on the oxidative stability of biodiesels obtained from various sources.

\section{Experimental}

Materials

For the synthesis of methyl biodiesel, soy, canola, corn, and microalgae refined oils were used. The microalgae oil was graciously provided by Dr. Fabio Batista (EXTRAEUNICAMP) and the other oils were purchased in the local market. Absolute methanol (Synth, Diadema, SP, Brazil) and sodium methoxide $30 \% \mathrm{~m} / \mathrm{m}$ in methanol (Vetec, RJ, Brazil) were used.

\section{Biodiesel synthesis}

The synthesis of the biodiesel was performed in three steps. First, with respect to the quantity of oil used, $16 \%$ $\mathrm{m} / \mathrm{m}$ of methanol and $0.58 \% \mathrm{~m} / \mathrm{m}$ of $30 \% \mathrm{~m} / \mathrm{m}$ sodium methoxide solution in methanol were mixed with the oil. The solution was maintained under reflux and mechanical stirring (900 rpm) and at a temperature of $60^{\circ} \mathrm{C}$ for an hour. Then, the reaction mixture was transferred to a separatory funnel for the separation of the glycerin phase. In the second step, the upper phase was returned to the reaction flask, to which more $4 \% \mathrm{~m} / \mathrm{m}$ of methanol and $0.14 \% \mathrm{~m} / \mathrm{m}$ of the catalyst solution were added (with respect to the initial mass of oil). The reaction was then carried out as in the first step.

In the third step, the biodiesel obtained in the second step was washed with five portions of water $(50 \mathrm{~mL})$ at $60{ }^{\circ} \mathrm{C}$ and then dried at $100{ }^{\circ} \mathrm{C}$ in an oven for 1 hour. The biodiesel was then passed through a column containing Amberlite BD10 Dry resin (Dow Chemical from Shanghai, China) to remove any impurities. In this scheme, $180 \mathrm{~g}$ of resin was employed per liter of biodiesel, and the percolation was performed at a flow rate of $4 \mathrm{~mL} \mathrm{~min}^{-1}$.

\section{Sample preparation}

To prepare the samples for the study of the influence of residual water and ultraviolet irradiation on the induction period, known volumes of water were added to $60 \mathrm{~mL}$ aliquots of biodiesel. Three samples of biodiesel with different water contents were prepared: biodiesel as obtained in the synthesis; biodiesel plus $12.9 \mu \mathrm{L}$ of water; biodiesel plus $25.8 \mu \mathrm{L}$ of water.

For the study of the influence of UV irradiation on the induction period, a $500 \mathrm{~W}$ mercury lamp, whose external glass bulb was removed, with emission between 250 and $577 \mathrm{~nm}$ was used. The aliquots of biodiesel were placed in an open flask and submitted to irradiation for 6 hours. The distance between the lamp and the biodiesel sample was 1 meter and the experiments were performed inside a laboratory hood.

\section{Analytical methods}

\section{Water content}

The water content was determined according to the EN ISO 12937 (2000) method, using a Metrohm Karl Fischer coulometric titrator model 831 KF. ${ }^{18}$ The measurements were performed in triplicate. 
Table 1. Biodiesels from canola, soy, linseed and microalgae oils, the respective water content and the induction period of oxidation (IP). Values are means of quadruplicates

\begin{tabular}{lcccccc}
\hline \multirow{2}{*}{ Biodiesel from } & \multicolumn{2}{c}{ "Pure" biodiesel } & \multicolumn{2}{c}{ Added $12.9 \mu \mathrm{L}$ of water } & \multicolumn{2}{c}{ Added $25.8 \mu \mathrm{L}$ of water $^{\mathrm{a}}$} \\
\cline { 2 - 7 } & Water content / $\mathrm{ppm}$ & $\mathrm{IP} / \mathrm{h}$ & Water content / ppm & $\mathrm{IP} / \mathrm{h}$ & Water content / $\mathrm{ppm}$ & $\mathrm{IP} / \mathrm{h}$ \\
\hline Canola & $267 \pm 23$ & $9.2 \pm 0.3$ & $440 \pm 10$ & $9.0 \pm 0.2$ & $609 \pm 6$ & $9.12 \pm 0.04$ \\
Soy & $249 \pm 4$ & $6.2 \pm 0.4$ & $534 \pm 5$ & $5.8 \pm 0.2$ & $684 \pm 9$ & $6.0 \pm 0.1$ \\
Linseed & $193 \pm 6$ & $1.91 \pm 0.03$ & $429 \pm 6$ & $1.91 \pm 0.02$ & $845 \pm 38$ & $1.91 \pm 0.02$ \\
Microalgae & $198 \pm 8$ & $7.62 \pm 0.09$ & $487 \pm 4$ & $7.6 \pm 0.1$ & $660 \pm 17$ & $7.7 \pm 0.1$ \\
\hline
\end{tabular}

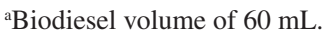

\section{Oxidative stability}

The induction period was determined following the EN 14112 (2003) method using a Metrohm Rancimat model 873 Biodiesel. ${ }^{16}$ The measurements were performed in quadruplicate, with the exception of the measurements of samples irradiated with ultraviolet light, which were performed in triplicate.

\section{Results and Discussion}

Influence of the water content on the induction period

The values of the induction period can be experimentally determined and used to evaluate the influence of water on the deterioration of the stored biodiesel because the IP is indicative of the oxidative deterioration over the storage time, even in time intervals along which other physicochemical properties do not change significantly. ${ }^{19}$

The biodiesel synthesized in this work presented water levels lower than the maximum allowed content, i.e., less than 500 ppm according to the EN ISO $12937^{18}$ and also to the Brazilian norm ANP No. $45,{ }^{20}$ which allows up to $350 \mathrm{ppm}$ of water in the distributor of the biodiesel. Thus, to study the influence of water on the induction period, it was necessary to add variable quantities of water to the aliquots of biodiesel to reach concentrations above the normalized limit.

Table 1 presents the respective water contents and induction periods of biodiesels obtained from canola, soy, linseed, and microalgae oils.

To evaluate whether there is a significant difference between the IP of biodiesels with respect to the added water, the paired Student's $t$-test (at a 95\% degree of confidence was applied). All calculated $t$-values were smaller than the tabulated value of 2.45 , indicating that there is no significant direct influence of the water present in the biodiesel on the IP, at least in the studied range of water concentration, i.e., approximately between 190 and $850 \mathrm{ppm}$ and within the experimental precision here obtained. These results are in agreement with those found by Bondioli et al. ${ }^{12}$ and Leung et al. ${ }^{13}$ These authors showed that the presence of residual water in biodiesel does not influence the acid number or the purity in terms of the ester content. However, exposure to air and to relatively high temperatures is the main factor that influences the degradation rate. Leung et al. ${ }^{13}$ suggested that the main factors causing biodiesel degradation are temperature and exposure to air, rather than humidity.

According to the results shown in Tables 1 and 2, the hydrolytic oxidation processes do not occur to a significant extent, even for biodiesel from linseed oil, which is highly unsaturated with an iodine number typically between 170 and $203 \mathrm{~g}$ per $100 \mathrm{~g} .{ }^{21}$ It is accepted that the higher the unsaturation of the ester molecules the more susceptible to oxidation is the biodiesel. , $^{3,4}$

\section{Influence of ultraviolet irradiation on the induction period}

Ultraviolet irradiation causes the formation of free radicals by abstracting an allyl or bis-allylic hydrogen atom, ${ }^{5}$ that initiate the oxidation processes of biodiesel with formation of degradation compounds such as aldehydes, ketones, and carboxylic acids, leading to the decrease in the IP of the biodiesel. ${ }^{22,23}$ Table 2 shows the IP values for biodiesel obtained from canola, soy, linseed, and microalgae oils after 6 hours of exposure to ultraviolet irradiation and without exposure to the radiation.

The statistical paired Student's $t$-test was applied at a $95 \%$ confidence level to investigate whether there was a

Table 2. Values of induction periods for "pure" biodiesels obtained from canola, soy, linseed and microalgae oils, obtained without irradiation of the samples and with $6 \mathrm{~h}$ of exposition to ultraviolet radiation

\begin{tabular}{lcc}
\hline Biodiesel & $\begin{array}{c}\text { Non-irradiated } \\
\text { IP / h }\end{array}$ & $\begin{array}{c}\text { Irradiated }^{\mathrm{b}} \\
\text { IP / h }\end{array}$ \\
\hline Canola & $9.2 \pm 0.3$ & $8.1 \pm 0.1$ \\
Soy & $6.2 \pm 0.4$ & $5.32 \pm 0.02$ \\
Linseeds & $1.91 \pm 0.03$ & $1.78 \pm 0.03$ \\
Microalgae & $7.62 \pm 0.09$ & $6.77 \pm 0.03$ \\
\hline
\end{tabular}

${ }^{\mathrm{a}}$ Experiments done in quadruplicates; bexperiments done in triplicates. 
Table 3. Values of induction periods (IP) of biodiesels prepared from canola, soy, linseed and microalgae oils, not irradiated and after UV irradiation without and with added water

\begin{tabular}{lcccc}
\hline & \multicolumn{2}{c}{ Without added water $^{\mathrm{a}}$} & \multicolumn{2}{c}{ With added water $^{\text {Biodiesel }}$} \\
\cline { 2 - 5 } & $\begin{array}{c}\text { Non-irradiated } \\
\text { IP / h }\end{array}$ & $\begin{array}{c}\text { Irradiated }^{\mathrm{c}} \\
\text { IP / h }\end{array}$ & $\begin{array}{c}12.9 \mu \mathrm{L} \text { water added and } \\
\text { irradiated IP / h }\end{array}$ & $\begin{array}{c}25.8 \mu \mathrm{L} \text { of water added and } \\
\text { irradiated IP / h }\end{array}$ \\
\hline Canola & $7.06 \pm 0.05$ & $5.86 \pm 0.06$ & $5.73 \pm 0.09$ & $5.83 \pm 0.07$ \\
Soy & $6.36 \pm 0.02$ & $6.0 \pm 0.1$ & $5.94 \pm 0.09$ & $6.05 \pm 0.06$ \\
Linseed & $1.81 \pm 0.01$ & $1.67 \pm 0.02$ & $1.53 \pm 0.03$ & $1.55 \pm 0.03$ \\
Microalgae & $6.8 \pm 0.2$ & $6.2 \pm 0.2$ & $5.9 \pm 0.2$ & $6.0 \pm 0.3$ \\
\hline
\end{tabular}

${ }^{\mathrm{a} S e e}$ Table 1 for water content; ${ }^{\mathrm{b}}$ values are means of quadruplicates; ${ }^{\mathrm{c}}$ values are means of triplicates.

significant difference in the IP of the irradiated samples with respect to the non-irradiated samples. All calculated $t$-values are higher than the tabulated $t$ of 2.57 . This result clearly shows that photo-oxidation of the irradiated samples occurred, leading to a decrease in the IP values.

Influence of ultraviolet irradiation on biodiesels with added water

To different aliquots of biodiesel were added 12.9 and $25.9 \mu \mathrm{L}$ of water, followed by exposure to ultraviolet light, with and without water, to investigate whether the presence of water influences the oxidative processes caused by this irradiation. Table 3 shows the IP values of the biodiesel obtained fromcanola, soy, linseed, and microalgae oils.

The statistical paired Student's $t$-test was applied at a $95 \%$ confidence level to evaluate whether there was a significant difference between the induction periods of the biodiesels with different amounts of water after UV irradiation during 6 hours. The results show a small but significant decrease in IP for the studied biodiesels. Also, by increasing the quantity of water in the biodiesels, beyond the concentration that came from the synthesis process, and irradiating with UV, additional tendency of decreasing of the value IP was observed indicating that water participates in the degradation photochemical reaction. Considering the precisions of the determinations, in the case of the linseeds oil biodiesel the participation of the water in the oxidation process is clearer.

\section{Conclusion}

The results show that, between 190 and $850 \mathrm{ppm}$ of water in the biodiesel, and without UV irradiation, no significant change in the IP values was observed under the experimental conditions. Therefore, under the experimental conditions used in this work, it can be supposed that hydrolytic processes caused by water did not occur to a significant extent to change the IP. However, irradiation by ultraviolet radiation for 6 hours significantly reduces the induction periods of the studied biodiesels and there is evidence that water participates in this degradation process.

\section{Acknowledgments}

The authors are grateful to CNPq for financial support and to Dr. Fabio Batista (EXTRAE-UNICAMP) who graciously provided the microalgae oil.

\section{References}

1. Lôbo, I. P.; Ferreira, S. L. C.; Cruz, R. S.; Quim. Nova 2009, 32, 1596.

2. Borsato, D.; Maia, E. C. R.; Dall'Antonia, L. H.; Silva, H. C.; Pereira, J. L.; Quim. Nova 2012, 35, 733.

3. Knothe, G.; Fuel Process. Technol. 2007, 88, 669.

4. Borsato, D.; Cini, J. R. M.; Silva, H. C.; Coppo, R. L.; Angilelli, K. G.; Moreira, I.; Maia, E. C. R.; Fuel Process. Technol. 2014, 127, 111.

5. Joshi, G.; Lamba, B. Y.; Rawat, D. S.; Mallick, S.; Murthy, K. S. R.; Ind. Eng. Chem. Res. 2013, 52, 7586.

6. Moser, B. R.; In Vitro Cell. Dev. Biol.: Plant 2009, 45, 229.

7. Paquette, G.; Kupranycz, D. B.; Van de Voort, F. R.; Can. Inst. Food Sci. Technol. J. 1985, 18, 112.

8. Chaithongdee, D.; Chutmanop, J.; Srinophakun, P.; Kasetsart J.: Nat. Sci. 2010, 44, 243.

9. Fattah, I. M. R.; Masjuki, H. H.; Kalam, M. A.; Hazrat, M. A.; Masum, B. M.; Imtenan, S.; Ashraful, A. M.; Renewable Sustainable Energy Rev. 2014, 30, 356.

10. Yaakob, Z.; Narayanan, B. N.; Padikkaparambil, S.; Unni, K. S.; Akbar, M. A.; Renewable Sustainable Energy Rev. 2014, 35, 136.

11. Canakci, M.; Monyem, A.; Van Gerpen, J.; Trans. ASAE 1999, 42, 1565.

12. Bondioli, P.; Gasparoli, A.; Lanzani, A.; Fedeli, E.; Veronese, S.; Sala, M.; J. Am. Oil Chem. Soc. 1995, 72, 699.

13. Leung, D. Y. C.; Koo, B. C. P.; Guo, Y.; Bioresour. Technol. 2006, 97, 250. 
14. Godoy, A. T.; Pereira, G. G.; Ferreira, L. L.; Cunha, I. B. S.; Barrera-Arellano, D.; Daroda, R. J.; Eberlin, M. N.; Alberici, R. M.; Energy Fuels 2013, 27, 7455.

15. Yang, Z.; Hollebone, P.; Wang, Z.; Yang, L. M.; Fuel Process. Technol. 2013, 106, 366.

16. EN 14112:2003: Fat and Oil Derivatives - Fatty Acid Methyl Esters (FAME); Determination of Oxidation Stability (Accelerated Oxidation Test); European Committee for Standardization (CEN): Brussels, Belgium, 2003.

17. Farhoosh, R.; Hoseini-Yazdi, S.; Food Chem. 2013, 141, 557.

18. EN ISO 12937:2000: Petroleum Products - Determination of Water - Coulometric Karl Fischer Titration Method; the International Organization for Standardization (ISO): Brussels, 2000.

19. Christensen, E.; McCormick, R.; Fuel Process. Technol. 2014, 128,339 .
20. Agência Nacional do Petróleo, Gás Natural e Biocombustíveis; Resolução ANP No. 45, http://ad.rosana.unesp.br/docview/ directories/Arquivos/Cursos/Apoio\%20Did\%C3\%A1tico/ Leonardo\%20Lataro\%20Paim/Quimica\%20Tecnologica/ ANP\%2045.pdf, accessed on July 05, 2016.

21. Firestone, D.; Physical and Chemical Characteristics of Oils, Fats, and Waxes, 2 ${ }^{\text {nd }}$ ed.; FDA: Washington DC, USA, 2006.

22. Ramalho, V. C.; Jorge, N.; Quim. Nova 2006, 29, 755.

23. Ambrosio, E.; Milano, L. M.; Souza, M. T. F.; Chiavelli, L. U. R.; Montanher, P. F.; Visentainer, J. V.; Almeida, V. C.; Souza, N. E.; Garcia, J. C.; J. Braz. Chem. Soc. 2014, 25, 759.

Submitted: April 18, 2016

Published online: July 7, 2016

FAPESP has sponsored the publication of this article. 